NBER WORKING PAPER SERIES

INTERDEPENDENT SECURITY: THE CASE OF IDENTICAL AGENTS

Howard Kunreuther

Geoffrey Heal

Working Paper 8871

http://www.nber.org/papers/w8871

NATIONAL BUREAU OF ECONOMIC RESEARCH

1050 Massachusetts Avenue

Cambridge, MA 02138

April 2002

We acknowledge support for this research from the U.S. Environmental Protection Agency under Cooperative Agreement C R 826583 with the University of Pennsylvania, the Wharton Risk Management and Decision Processes Center and the Columbia University Earth Institute. We are particularly grateful to Richard Zeckhauser for helpful discussion and comments on an earlier draft. Useful insights were also provided by Mark Broadie, Ido Erev, Victor Goldberg, Daniel Kahneman, Paul Kleindorfer, Felix Oberholzer-Gee, Yechiam Yemini and participants in the NBER Insurance Project Workshop where this paper was presented. The views expressed herein are those of the authors and not necessarily those of the National Bureau of Economic Research.

(C) 2002 by Howard Kunreuther and Geoffrey Heal. All rights reserved. Short sections of text, not to exceed two paragraphs, may be quoted without explicit permission provided that full credit, including $(\mathrm{C}$ notice, is given to the source. 
Interdependent Security: The Case of Identical Agents

Howard Kunreuther and Geoffrey Heal

NBER Working Paper No. 8871

April 2002

JEL No. C7, H2, D62

\begin{abstract}
Do firms have adequate incentives to invest in anti-terrorism mechanisms? This paper develops a framework for addressing this issue when the security choices by one agent affect the risks faced by others. We utilize the airline security problem to illustrate how the incentive by one airline to invest in baggage checking is affected by the decisions made by others. Specifically if an airline believes that others will not invest in security systems it has much less economic incentive to do so on its own. Private sector mechanisms such as insurance and liability will not necessarily lead to an efficient outcome. To induce adoption of security measures one must turn to regulation, taxation or institutional coordinating mechanisms such as industry associations. We compare the airline security example with problems having a similar structure (i.e., computer security and fire protection) as well as those with different structures (i.e., theft protection and vaccinations). The paper concludes with suggestions for future research.
\end{abstract}

Howard Kunreuther

Wharton School

University of Pennsylvania

Philadelphia, PA 19104,

Visiting Research Scientist

Columbia University,

and NBER

kunreuther@wharton.upenn.edu
Geoffrey Heal

Graduate School of Business

Columbia University

New York, NY 10027

and NBER

gmh1@columbia.edu 


\section{Interdependent Security: The Case of Identical Agents}

\section{Howard Kunreuther \\ Geoffrey Heal}

\section{Introduction}

Security is topical. Many individuals and organizations are considering whether to invest more in security precautions. In this paper we investigate the economic incentives for such investment. Do individuals and firms have incentives to carry out socially appropriate levels of security investment? Or are there instead reasons to suppose that they will systematically underinvest in this area? Ayres and Levitt (1998) have demonstrated the social benefits of protection when individuals invest in unobservable precautionary measures such as the LoJack car retrieval system that criminals cannot detect. Interestingly, they suggest that the social benefits here greatly exceeded the private benefits. This might naturally suggest a sub-optimal level of private investment.

In this paper we also show that in situations where the security levels of members of a group are interdependent, there are positive externalities associated with investing in protection. However, in contrast to expenditures on crime protection, the incentives to invest in security may be perverse: the dependence of one agent's security on the behavior of others may completely negate the payoffs it receives from its own investment in protective measures. We shall refer to these cross-effects between one agent's incentives and the behavior of the others as contamination. 
We shall illustrate our general argument by reference to an airline that is considering whether to install a baggage checking system voluntarily for added protection. In making this decision it needs to balance the cost of installing and operating such a system with the reduction in the risk of an explosion from a piece of luggage not only from the passengers who check in with it, but from the bags of passengers who check in on other airlines and then transfer to it.

As we will show below, the incentive to invest in security is greatly diminished if other airlines fail to adopt protective measures. The decision by all agents to remain unprotected may be a Nash equilibrium, even though from both the vantage points of each individual unit and of society as a whole there are net benefits to everyone from investing in protection. We will focus primarily on the airline security case, but will show below that there are several other interesting and topical problems that have similar, though subtly different, analytical structures.

One of these problems concerns the security of a computer network. It is generally the case that once a hacker or virus reaches one computer on a network, the remaining computers can be more easily compromised. Because of this possibility of contamination the incentive that any one computer owner has to secure his machine is reduced if he believes that other machines on the network will be insecure. Another analytically similar problem concerns fire safety in apartment buildings - the risk that an apartment faces depends on the chance of a fire originating domestically coupled with the risk of a fire starting elsewhere and spreading. The incentive a homeowner has to take fire precautions, such as installing a sprinkler, depends on her expectations about the policies that will be chosen by other residents in the building. In both of these cases the expectation that others will not adopt security measures reduces the incentive that a particular agent has to invest in security, in some cases to zero. 
To our knowledge this problem of interdependent security has not been examined in the literature. Orszag and Stiglitz (2002) develop a model for the optimal size of a fire department and point out that homeowners fail to take into account the positive externalities associated with reducing damage to their neighbors by building safer homes. They also note that an increase in government investment in security will tend to reduce individual investment. What they do not show is that the economic incentives for investing in preventive measures decrease as the number of unprotected homes increases. There is thus a need for either public sector intervention or coordinating mechanisms to induce this activity and reduce the need for larger fire departments.

One question that the present paper addresses is how to induce tipping mechanisms as characterized by Schelling (1968). In other words, how can we ensure that enough agents will invest in security so that all the others will follow suit? At some level this aspect of the problem is similar to the phenomena that arise with network externalities, where a community will standardize on one of several competing products after enough members have adopted this. (Arthur, 1994; Heal, 1999). In this context the incentive for any agent to invest in security is an increasing function of how many others have already done so. Once a critical mass has invested, then all others will want to do the same. ${ }^{1}$

The next section of the paper develops a model of agents whose security is interdependent. It illustrates the nature of the externalities that create a disincentive to invest in protection. This model is based on the airline scenario outlined above. Section 3 discusses how one can internalize these externalities through intervention by the public sector and/or by coordinating mechanisms. In Section 4 we examine other forms of protection, namely computer

\footnotetext{
${ }^{1}$ See Heal $(1994,1999 b)$ for a similar concept of "minimum critical coalition" in the context of interdependency via environmental externalities.
} 
security measures, fire protection systems, burglar alarms and vaccines to see in what ways these differ from the model characterizing airline security. The concluding section discusses future research.

\section{A Model of Interdependent Security}

We consider a 1 period model where there are $n$ risk-neutral agents designated as $A_{i} \quad i=1 \ldots n$. These are the primary actors who have to choose whether or not to invest in security. This is taken to be a discrete choice: they either invest or do not invest. In the airline scenario, these are airlines choosing whether or not to invest in a baggage screening system for luggage that is being checked.

Each agent faces a risk of damage; if the damage materializes then the loss is $L$. There are two possible ways in which damage can occur: it can start either on the agent's own property or on the property of another agent. The probability of damage arising on the agent's own property if it has not invested in security precautions is $p$, so that the expected loss from this event is $p L$. If it has invested in security precautions then this risk is zero. The situation is completely symmetric and all agents are identical.

As we noted, damage to an agent may arise from an agent's own property or from the property of another. For the airline scenario, thorough scanning of baggage that an airline has checked itself will prevent damage from these bags, but there could still be an explosive in a bag transferred from another airline. There is therefore an additional risk of loss due to contamination from other agents who have not invested in loss prevention. In the airline case, these probabilities are interpreted as follows. The probability that a bag containing a bomb will be checked onto an airline without a security system is $p$. The probability that a dangerous bag, 
once accepted for carriage by one airline, is transferred by it to another is denoted by $q$. If there are $n \geq 2$ airlines, the probability that this bag will be transferred from airline $i$ to airline $\mathrm{j}$ is $q /(n-1)$.

We assume throughout that the damages that result from multiple security failures are no more severe than those resulting from a single failure, so that the damages are not additive. In the airline baggage scenario, this amounts to an assumption that one act of terrorism is as serious as several. ${ }^{2}$ The key issue is whether or not there is a failure, not how many failures there are. We could almost think of the definition of a catastrophe as being an event so serious that it is difficult to imagine an alternative event with greater consequences. We focus first on the case of two agents, as this presents the basic intuitions in a simple framework, and then turn to the multiagent case.

\section{The 2- Agent Problem}

Assume that each agent has two choices: to invest in security, $\mathbf{S}$, or not to do so, N. Think of $\mathbf{S}$ as investing in baggage screening, and $\mathbf{N}$ as not doing so. Table 1 shows the payoffs to the agents for the four possible outcomes:

Table 1: Expected Costs Associated with Investing and Not Investing in Security

Agent $1\left(A_{1}\right)$

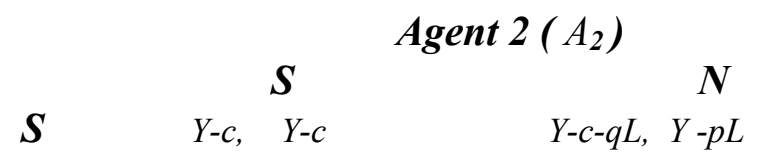

$$
\boldsymbol{N} \quad Y-p L, \quad Y-c-q L \quad Y-[p L+(1-p) q L], Y-[p L+(1-p) q L]
$$

Here $Y$ is the income of each agent before any expenditure on security or any losses from the risks faced. The cost of investing in security is $c$. The rationale for these payoffs is straightforward. If both invest in security, then each incurs a cost of $c$ and faces no losses from

\footnotetext{
${ }^{2}$ One act of terrorism was sufficient to lead to the demise of Pan American Airways. The destruction of Pan Am flight 103 in 1988 was due to a bomb checked in on another airline and then transferred to Pan Am. (http://www.cbc.ca/news/indepth/lockerbie/investigation.html)
} 
damage so that their net incomes are $Y$-c. If $\mathrm{A}_{1}$ invests and $\mathrm{A}_{2}$ does not (top right entry) then $\mathrm{A}_{1}$ incurs an investment cost of $c$ and also runs the risk of a loss from damage emanating from $\mathrm{A}_{2}$. The probability of $\mathrm{A}_{2}$ contaminating $\mathrm{A}_{1}$ is $q$, so that $\mathrm{A}_{1}$ 's expected loss from damage originating elsewhere is $q L$. This cost represents the negative externality imposed by $\mathrm{A}_{2}$ on $\mathrm{A}_{1}$. In this case $\mathrm{A}_{2}$ incurs no investment costs and faces no risk of contagion but does face the risk of damage originating at home, $p L$. The lower left payoffs are just the mirror image of these.

If neither agent invests, then both have an expected payoff of $Y-p L-(1-p) q L$. The term $p L$ here reflects the risk of damage originating at home. The term $q L$, that shows the expected loss from damage originating at the other agent and transferred elsewhere, is multiplied by $(1-p)$ to reflect the assumption that the damage can only occur once. So the risk of contagion only matters to an agent in the case in which that agent does not suffer damage originating at home.

Now that the payoffs have been specified, we can ask the natural question: under what conditions will the agents invest in security? It is clear from Table 1 that for investment in security to be a dominant strategy, we need

$$
Y-c>Y-p L \quad \text { and } Y-c-q L>Y-p L-(1-p) q L
$$

The first inequality just says that $c<p L$, that is, the cost of investing in security must be less than the expected loss, a natural condition for an isolated agent. The second inequality is more interesting: it reduces to $c<p L-p q L=p L(1-q)$. This is clearly a tighter inequality reflecting the possibility of contagion from the second agent. This possibility reduces the incentive to invest in security. Why? Because in isolation investment in security buys the agent complete freedom from risk; with the possibility of contagion it does not. Even after investment there remains a risk of damage emanating from the other agent. Investing in security buys you less when there is the possibility of contamination from others. 
In the 2-agent problem with identical costs we can determine the optimal behavior of each agent if they both make decisions simultaneously without any communication. In this noncooperative environment if $c<p L(1-q)$, then both agents will want to invest in protective measures (S,S); if $c>p L$ then neither agent will want to invest in protection $(\mathbf{N}, \mathbf{N})$. If $p L<c<p L$ $(1-q)$ then there are two Nash equilibria $(\mathbf{S}, \mathbf{S})$ and $(\mathbf{N}, \mathbf{N})$ and the solution to this game is indeterminate.

This solution concept is illustrated below with a numerical example. Suppose that $p=.1$, $q=.2, L=1000$ and $\mathrm{c}=95$. The matrix in Table 1 is now represented as Table 2.

\section{Table 2: Expected Costs Associated with Investing and Not Investing in Security for Illustrative Example}

\begin{tabular}{cccccc} 
& \multicolumn{4}{c}{ Agent 2 $\left(A_{2}\right)$} \\
Agent $1 \quad\left(A_{1}\right)$ & $\boldsymbol{S}$ & $Y-95$, & $Y-95$ & $Y-295, Y-100$ \\
& & $N$ & $Y-100, Y-295$ & $Y-280, Y-280$
\end{tabular}

One can see that if $A_{2}$ has protection (S), then it is worthwhile for $A_{1}$ to also invest in security since its expected losses will be reduced by $p L=100$ and it will only have to spend 95 on the security measure. However, if $A_{2}$ does not invest in security $(\mathbf{N})$, then there is still a chance that a loss will occur to $\mathrm{A}_{1}$. Hence the benefits of security to $\mathrm{A}_{1}$ will only be $p L(1-q)=80$ which is less than the cost of the protective measure. Hence $A_{1}$ will not want to invest in protection. In other words, either both agents invest in security or neither of them do so. These are the two Nash equilibria.

\section{Multiple agents}

Now we move on to the more general case of $n$ identical agents all symmetrically placed. Think of many airlines exchanging baggage at a large hub. If all but one of the agents has invested in security, then the position of the remaining one is identical to its position in isolation: 
there is no risk of contagion. At the other extreme, suppose none of the other $n-1$ agents have invested; then if the remaining agent is protected it still faces risks originating at $n-1$ other locations.

We begin by illustrating the argument with the case of three agents, denoted $A_{i} i=1,2,3$. Interpret them for concreteness as airlines deciding whether or not to install baggage security systems where bags are only transferred once between airlines. In how many ways can airline 1 $\left(A_{1}\right)$ be victim of a bomb attack if it has instituted a baggage security system but none of the other airlines have done so? In other words, what are the negative externalities associated with contamination from other airlines? Airline 1 can suffer damage from a bag checked onto $\mathrm{A}_{2}$ and then transferred to $\mathrm{A}_{1}$. This event occurs with probability $q / 2$ since we assume that the bag from airline 2 has an equal chance of being transferred to either $A_{1}$ or $A_{3}$. A bomb-laden bag from $A_{3}$ can also damage $A_{1}$. This can occur when $A_{2}$ does not transfer a dangerous bag to $A_{1}$ but $A_{3}$ does. This event occurs with probability $(1-q / 2) q / 2$. Since all agents are identical the negative externalities are the same for every airline.

Define $X(3,0)$ as the expected negative externality to any airline $\mathrm{i}$ that has installed a baggage checking system if there are 3 airlines and none of the others have instituted this security measure. $X(3,0)$ is given by $(q / 2)[1+(1-q / 2)] L$. When one other airline has installed a security measure then the expected negative externality $X(3,1)$ is given by $(q / 2) L$ since there is only one 1 airline without a security system and it can ship a contaminated bag with probability $q / 2$ to airline $\mathrm{i}$.

If there are four airlines then the expected negative externalities become:

$$
\begin{aligned}
& X(4,2)=(q / 3) L \\
& X(4,1)=(q / 3)[1+(1-q / 3)] L \\
& X(4,0)=(q / 3)\left[1+(1-q / 3)+(1-q / 3)^{2}\right] L
\end{aligned}
$$


For $n>1$ agents this generalizes to

$$
X(n, 0)=[q /(n-1)] \sum_{t=0}^{n-2}\left[[1-q /(n-1)]^{t}\right] L=\left\{1-[1-q /(n-1)]^{n-1}\right\} L
$$

The limit of this expression as $n$ tends to infinity is

$$
\operatorname{Lim}_{n \rightarrow \infty} X(n, 0)=\left(1-e^{-q}\right) L
$$

We can summarize this in the following proposition:

Proposition 1: If there are n agents none of whom have invested in security, then the expected loss inflicted on any one by all others is $X(n, 0)=\left\{1-[1-q /(n-1)]^{n-1}\right\} L$. As $n$ increases this converges to $\left(1-e^{-q}\right) L$

If $q=0$ then $X(n, 0)$ is zero; $X(n, 0)$ increases monotonically in $q$ reaching its largest value of $0.63 \mathrm{~L}$ when $q=1$. Intuitively this makes sense: with no chance of baggage transfer there is no negative externality; if bags are transferred to other airlines with probability one then the expected negative externality to any airline is $63 \%$ of the possible loss. For a given value of $q$, the term $X(n, 0)$ decreases monotonically as $n$ increases, taking on the value of $q L$ for $n=2$ and falling to $\left(1-e^{-q}\right) L$ as $n$ approaches infinity. So the externality is largest when there is only one other airline and decreases as the number of airlines rises. Again there is an obvious intuition here: as the number of airlines increases, the chance of a transferred bag reaching any particular airline falls. Figure 1 shows how the externality decreases with $\mathrm{n}$ from 2 to 100 for $q=.3$ (upper line, dashed) and $q=.2$ (lower line, solid) when $\mathrm{L}=1$. 


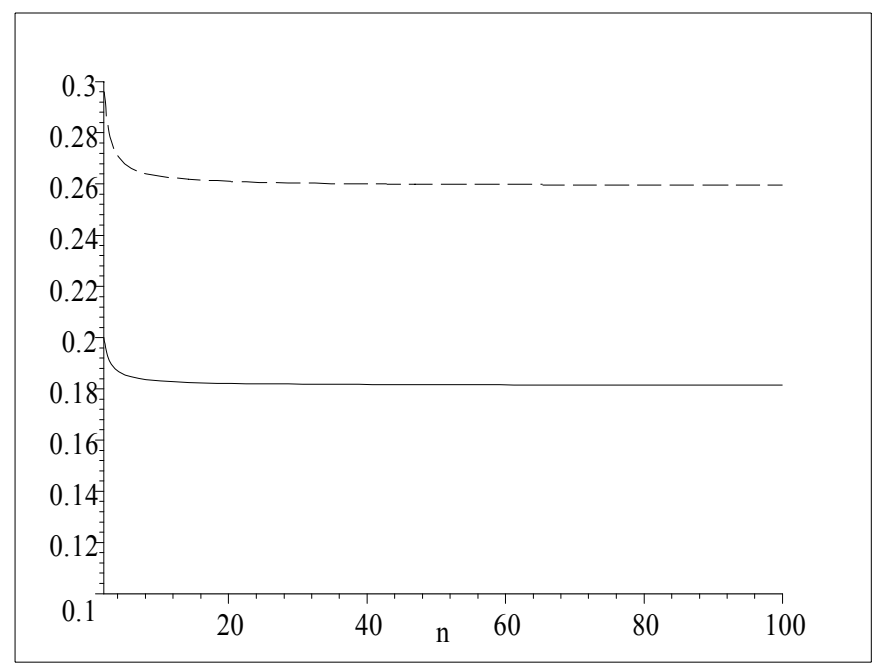

Figure 1: $X(n, 0)$ for $L=1$ and $q=0.2$ or $\mathrm{q}=0.3$

When there are $n$ firms in total, the payoff to $\mathrm{A}_{1}$ from not investing in security when the other $n-1$ are also not investing is

$$
Y-p L-(1-p) X(n, 0)
$$

The payoff from $\mathrm{A}_{1}$ investing is

$$
Y-c-X(n, 0)
$$

Hence investing is the better strategy if and only if

$$
c<p[L-X(n, 0)]
$$

This implies that there is less incentive to invest in protection with higher negative externalities associated with contamination. So from Figure 1 we see that the upper bound on $c$ rises with $n$ and the incentive to invest increases.

What is the structure of the set of possible Nash equilibria? Return to Table 1. As we have already seen, $(\mathbf{S}, \mathbf{S})$ is a dominant strategy equilibrium if $c<p L(1-q)$. (S,S) is a Nash equilibrium if $c<p L$, a weaker condition. (N,N) is a dominant strategy equilibrium if $c>p L$ and a 
Nash equilibrium if $c>p L(1-q)$. There is an interval $p L(1-q)<c<p L$ in which both $(\mathbf{S}, \mathbf{S})$ and $(\mathbf{N}, \mathbf{N})$ are Nash equilibria.

Could there be other Nash equilibria in this game? The answer is no, at least as long as all agents are identical. In the two agent case for $(\mathbf{N}, \mathbf{S})$ to be an equilibrium it is necessary that $Y$ $p L>Y-c$ or $c>p L$ and also $Y-c-q L>Y-p L-(1-p) q L$ or $c<p L(1-q)$ which is obviously impossible. So the only equilibria are where both agents invest or both do not invest. Does this change as the number of agents increases? It does not: even with many identical agents, they all will choose the same strategy at a Nash equilibrium.

Proposition 2: Consider a Nash equilibrium in the n-agent problem $(\mathrm{n}>2)$ defined above (each agent has two strategies $\mathbf{N}$ and $\mathbf{S}$ with payoffs described by equation (1)). At such a Nash equilibrium all agents will choose the same strategy.

Proof. Assume to the contrary that $(\mathbf{S}, \mathbf{S}, \ldots . . . \mathbf{S}, \mathbf{N})$ is a Nash equilibrium. Without loss of generality we assume the last agent chooses $\mathbf{N}$ and all others choose $\mathbf{S}$. Then for all agents from 1 to $n-1$ this implies that the strategy $\mathbf{S}$ is a best response to $n-2$ agents choosing $\mathbf{S}$ and one choosing $\mathbf{N}$. But for agent $n, \mathbf{N}$ is the best response if there are $n-1$ agents choosing $\mathbf{S}$. However if $\mathbf{S}$ is a best response to $n-2$ agents choosing $\mathbf{S}$ and $l$ agent choosing $\mathbf{N}$, then it is also a best response to $n-1$ agents choosing $\mathbf{S}$; changing one choice from $\mathbf{N}$ to $\mathbf{S}$ will reduce the externality on all other agents and increase the incentive to choose $\mathbf{S}$. This contradicts the assumption that agents choose differently at a Nash equilibrium. The same argument can be applied to cases in which more than one agent chooses a divergent strategy.

Note that if the agents have different costs of investing in security measures, then even in the 2agent case we may find an equilibrium where one agent one invests in security and the other 
does not. Specifically, let $c_{1}$ and $c_{2}$ be the costs of the two agents: then $(\mathbf{N}, \mathbf{S})$ will be a Nash equilibrium if $c_{1}>p L$ and $c_{2}<p L(1-q)$. This requires that the two costs differ by at least $p q L$.

There are three critical values of $c$ that need to be considered in determining the nature of the equilibria when there are $n$ agents in the system. Let $c^{* *}$ represent the value of $c$ above which all agents will be indifferent between investing and not wanting to invest in protection. This will occur if there are no externalities so that each agent captures all the benefits of protection. In other words, $c^{* *}=p L$ and is invariant to the number of agents in the system. Let $c^{*}(n, 0)$ represent the value of $c$ below which an agent will want to invest in security if none of the other $n-1$ agents are protected. Then $c^{*}(n, 0)=p[L-X(n, 0)]$. For the above example where $L=1000, p=.1$ and $q=.2$, if there are $n=10$ airlines, $X(10,0)=18.4, c^{* *}=100$ and $c^{*}(10,0)=81.6$. If $c>100$ then the only Nash equilibrium is $(\mathbf{N}, \mathbf{N}, \ldots \mathbf{N})$ and none of the agents will want to invest in protection. If $c<81.6$ then the only Nash equilibrium is $(\mathbf{S}, \mathbf{S}, \ldots . . \mathbf{S})$. For $81.6 \leq c \leq 100$ there are two Nash equilibria $(\mathbf{N}, \mathbf{N}, \ldots . \mathbf{N})$ and $(\mathbf{S}, \mathbf{S}, \ldots . . . \mathbf{S}){ }^{3}$

\section{Implications of the Solution}

The problem of encouraging individuals to adopt protective measures resembles the prisoner's dilemma problem in the sense that it is often advantageous for all agents to adopt protection for both themselves and society, but none of them have an economic incentive to do so on their own. A classic prisoner's dilemma is where each firm has a cost incentive to undertake some activity (e.g. polluting the environment). It knows that if there were a coordinating mechanism so that none of them engaged in this activity, they would each be better off economically while at the same time improving social welfare. (e.g., firms' profits would be higher and the air and/or water would be cleaner.)

\footnotetext{
${ }^{3}$ When $c=81.6$ any agent is indifferent between investing and not investing if none of the other agents have invested in security. Similarly if $c=100$ then any agent is indifferent between investing and not investing if all of the other agents have invested in security.
} 
For certain cost structures the interdependent security problem has the same characteristics as a prisoner's dilemma. More specifically in the 2-agent case if $p L<c$ then each agent prefers not to invest in security $[$ i.e. $(\mathbf{N}, \mathbf{S})>(\mathbf{S}, \mathbf{S})$ for agent 1 and $(\mathbf{S}, \mathbf{N})>(\mathbf{S}, \mathbf{S})$ for agent 2] leading to a single Nash equilibrium at $(\mathbf{N}, \mathbf{N})$. However, if $p L+(1-p) q L>c$ then both agents would be better off at $(\mathbf{S}, \mathbf{S})$ than at $(\mathbf{N}, \mathbf{N})$.

For other situations where $p L>c$ but $c>p L(1-q)$ as illustrated in Table 2, the interdependent security problem differs from the prisoner's dilemma, since there are two Nash equilibria $(\mathbf{S}, \mathbf{S})$ and $(\mathbf{N}, \mathbf{N})$. Now, for example, if agent 1 can convince agent 2 to invest in security, there will be an economic incentive for agent 1 to voluntarily follow suit. In the context of multiple agents, an airline is more likely to invest in a baggage checking system if it knows that some of the other airlines have taken this step. Their risk is now more under their own control and more affected by their investment in security. The challenge is how to internalize the externality for some or all the agents, so a typical agent is willing to invest in security.

\section{Internalizing Externalities}

The only ways to encourage agents to invest in security when they face the possibility of contamination from others is to develop a set of economic incentives (either positive or negative) that makes it more attractive for some or all of the involved individuals to take protective actions. Below we examine a set of different measures ranging from private market mechanisms to regulations to collective choice that may internalize the externalities associated with protective measures where there are interdependencies between agents.

\section{Insurance}

Insurance appears to be a logical way for encouraging security since it rewards those who adopt protective measures by reducing their premium to reflect the lower risk. However, in order 
to deal with the externalities created by others who do not invest in protection, the agent causing the damage must be forced to pay for the losses. For example, if a bag transferred from Airline 1 to Airline 2 exploded, Airline 1's insurer would have to pay for the cost of the damage to 2. This is not how current insurance practice operates. An insurer who provides protection to $A_{i}$ is responsible for losses incurred by agent i no matter who caused them. ${ }^{4}$ One reason for this contractual arrangement between insurer and insured is the difficulty in assigning causality for a particular event. ${ }^{5}$

Interestingly enough a monopolistic insurer would want to internalize the externality if it were providing coverage to all agents. An agent who adopted a protective measure would be given premium reductions not only for the reduced losses to its own unit but also for the reduction in losses to others. Social insurance programs have the advantage over a competitive insurance market in encouraging this type of protection. Under such a program as long as $c<p L$, there would be an incentive for all agents to invest in security and the Nash equilibrium would be $(\mathbf{S}, \mathbf{S}$......S).

\section{Liability}

If an agent who caused damage to other agents by not adopting a protective measure were held liable for these losses, then the legal system would offer another way to internalize the externality due to interdependent security. However we do not know of any cases where an agent has been held liable for the damages to another agent because he did not invest in protection. In the case of the airline example, it would be difficult to know whether an unchecked bag from

\footnotetext{
${ }^{4}$ If the damage from an insured risk is due to negligence or intentional behavior then there are normally clauses in the insurance policy that indicate that losses are not covered (e.g. a fire caused by arson).

${ }^{5}$ With respect to fire damage a classic case is H.R. Moch Co., Inc. v Rensselaer Water Co. 247N.Y.160, 159 N.E. 896 which ruled that "A wrongdoer who by negligence sets fire to a building is liable in damages to the owner where the fire has its origin, but not to other owners who are injured when it spreads". We are indebted to Victor Goldberg who provided us with this case.
} 
another airline caused damage to the plane or whether it was due to one of the airline's own bags. The costs of settling these disputes appear to favor a liability system where each agent is responsible for its own losses unless there is a clear case of negligence on the part of some other agent.

\section{Taxation}

A more direct way of encouraging greater security is to levy a tax of $t$ dollars on any entity that does not invest in protection. In the case of identical agents one would want the tax to be high enough so that the only Nash equilibrium would be (S,S....S). The magnitude of the tax depends on the number of agents and the cost of protection, $c$.

Suppose that there are $n$ agents in the pool and none of them have invested in security. The government wants to determine the minimal tax $t^{*}$ to induce each agent to protect itself. As shown in section 2 the costs to an agent who invests in protection will be

$$
c+X(n, 0)
$$

If an agent does not invest in protection and is taxed $t$ dollars, its cost will be

$$
p L+(1-p) X(n, 0)+t
$$

Hence for any agent to want to invest in protection when no one else does, the tax must be high enough so that

$$
t>c-p[L-X(n, 0)]
$$

If $c \leq p(L-X(n, 0))$ then there is no need to impose any tax on an agent for it to want to invest in protection. Hence

$$
t^{*}=\max \{0, c-p(L-X(n, 0)]\}
$$

Consider the illustrative airline example where $n=10$ and $X(10,0)=18.6$. If $t=0$, then an agent will only invest in security if no one else does when $c<p[L-X(10,0)]=81.4$. If $\quad c>81.4$, 
then $t^{*}=c-81.4 .^{6} \quad$ Note that a subsidy on protective measures plays the identical role in inducing agents to invest in security as does a tax. The cost $c$ is reduced due to the subsidy, so that the protective measure is more attractive to the agent.

\section{Regulations and Standards}

The possibility of contamination by other units provides a rationale for well-enforced regulations and standards that require individuals and firms to adopt protective mechanisms. The need for baggage review systems took on greater importance after the Sept. $11^{\text {th }}$ tragedies and has led the government to require their use by the airlines. The U.S. Congress now requires all airlines to have a checked baggage security program to screen all bags for bombs (NY Times 2002).

Building codes for reducing damage from natural disasters are standard in most hazardprone states and can be justified in part by the externalities associated with damage from a disaster [Cohen and Noll (1981)]. When a building collapses it may create externalities in the form of economic dislocations and other social costs that are beyond the economic loss suffered by the owners. These may not be taken into account when the owners or developers evaluate the importance of adopting a specific mitigation measure [Kleindorfer and Kunreuther (1999)].

\section{Coordinating Mechanisms}

One way to convince the $n$ independent agents that it would be in everyone's best interests to invest in protection is to utilize some official organization to coordinate these decisions. For example, the International Air Transport Association (IATA), the official airline association, has indicated on its Web site that since Sept. $11^{\text {th }}$ they "have intensified hand and

\footnotetext{
${ }^{6}$ Suppose that $c>c^{* *}$ so that there is no incentive for any agent to invest in protection even if all other $n-1$ agents have protected themselves. If there are additional indirect benefits from protection besides a reduction in the expected loss $(\mathrm{pL})$, then the government may want to impose a tax on unprotected agents that is high enough to induce everyone to protect themselves.
} 
checked baggage processing". IATA could have made the case to all the airlines that they would be better off if each one of them utilized internal baggage checking so that the government would not have had to require this.

An association can play a coordinating role by stipulating that any member has to follow certain rules and regulations including the adoption of security measures and has the right of refusal should they be asked to do business with an agent that is not a member of the association and/or has not subscribed to the ruling. IATA could require all bags to be reviewed carefully and each airline could indicate that it would not accept in-transit bags from airlines that did not adhere to this regulation.

Apparently IATA follows this type of policy in agreements regarding pricing policies. If an airline does not belong to IATA and you want to transfer to this airline from an originating IATA airline, the originating airline will not make a reservation for you. Furthermore an IATA airline will not honor a non-IATA airline ticket unless it conforms to the IATA tariff conference (e.g. US Air would not honor a JetBlue airline ticket). ${ }^{7}$

On a more informal level it might be possible to establish social norms by organizations that generate pressure to invest in protection (Sunstein 1996). This is not easy to do since there are normally no visible benefits from the investment until a disaster occurs. To the extent that opinion leaders can convince others in their community that these investments will yield expected benefits to everyone in the form of lower losses and higher property values, such a strategy may work. ${ }^{8}$

\footnotetext{
${ }^{7}$ See the IATA web site at http://www.iata.org/membership/steps.asp\#10

${ }^{8}$ See Ostrom (1990), particularly chapter 6 that deals with the conditions under which norms evolve governing the use of common property resources.
} 


\section{Relationship to Other Forms of Protection}

In this section we examine other forms of protection to determine their similarities to and differences from the airline security problem. We first examine other types of interdependent security problems, namely computer viruses and fires that spread. We then turn to theft protection and vaccinations.

\section{Computer Security}

Protecting computer networks from viruses and from hackers is similar to investing in airline security. Each agent on the network can make its own investment in protection, but the effectiveness of this investment depends on those made by others. There is however one major difference. If one computer is unprotected then malicious external agents could attack the entire system via this one computer. A hacker who gains access to a network via one weak link can in many cases compromise all computers on the network. In other words, one unprotected node can endanger all the other nodes even if they have invested in protection. ${ }^{9}$ In the airline security problem only one plane can be affected by a contaminated piece of luggage.

As one unprotected computer can impact all $n-1$ other computers whether or not they are protected, the expected negative externalities associated with the computer security problem are much greater than for airline security. More specifically if computer $\mathrm{i}$ is protected and all the other $n-1$ computers are not then

$$
X(n, 0)=q L \sum_{\mathrm{t}=0}^{\mathrm{n}-2}\left[(1-q)^{t}\right]=\left[1-(1-q)^{n-1}\right] L
$$

As the number of agents increases without limit then

$$
X(n, 0)=q L \sum_{\mathrm{t}=0}^{\infty}\left[(1-q)^{t}\right]=q L /[1-(1-q)]=L
$$

\footnotetext{
${ }^{9} \mathrm{We}$ are indebted to Yechiam Yemini for this information.
} 
This implies that in the limit $c<p[L-X(n, 0)]=0$ so that investing in computer security can never be a dominant strategy as long as the cost of protection is positive. Formally we can now state:

Proposition 3: In an interdependent security problem where one compromised agent can contaminate all others, investment in security can never be a dominant strategy if its cost is positive.

A comparison of Proposition 3 with the equivalent result given by Proposition 1 for the airline case is instructive. When $n=2$ the two cases are by definition the same. For $n=\infty$ and $q=1$ the airline negative externality is $0.63 \mathrm{~L}$ whereas in the computer network case the number is just $L$. Setting $q=1$ gets the airline case as close as possible to the computer network case: when $q=1$ there is bound to be an externality between agents, but the intensity is reduced because the impact is restricted to a single agent.

\section{Fire Protection}

Investing in sprinkler systems in an apartment in a multi-unit building to reduce the potential losses from fire has a similar structure to the computer security problem. A fire that starts in an unprotected apartment can spread to other units and damage them whether or not they have sprinkler systems installed. If a fire in any unit could spread to all the other units simultaneously then this problem would be identical in structure to a computer virus. In reality a fire normally destroys units only on the same or adjacent floors of buildings. ${ }^{10}$ Hence any apartment unit in the building would only be subject to damage from at most $m$ of the $n$ units in the building. In this case suppose apartment 1 was protected with a sprinkler system and all the

\footnotetext{
${ }^{10}$ One of us, Heal, lives in an apartment building and was recently told by the building's insurance agent that a serious fire usually destroys the floor on which it starts, and damages two floors above via smoke and flames and two below are harmed through water damage from putting the fire out.
} 
other $m$ units surrounding it were unprotected. Then the negative externalities it would incur would have an expected value given by

$$
X(n, 0)=q L \sum_{\mathrm{t}=0}^{\mathrm{m}-1}\left[(1-q)^{t}\right]
$$

As the number of units $m$ that can impact on a given apartment decreases, then $X(n, 0)$ also decreases and the apartment unit will be more likely to invest in protection.

\section{Theft Protection}

Consider the case where a burglar is considering which one of a set of identical houses in a neighborhood to rob. His concern is the chance of being caught in attempting to break into the house. By installing a burglar alarm you increase the chance that the intruder will be detected. If you announce publicly with a sign that your house has been protected, then the burglar will look for greener pastures to invade. In other words, installing a burglar alarm in your house, and announcing it, decreases the chances that your house will be robbed and increases the chance that other unprotected homes will be targets for the thief. ${ }^{11}$

Let $p$ be the probability of a loss $(L)$ to any house when none of the homes in the area have invested in protection. For example, if a thief randomly chooses one of the $n$ houses in the area as a target, then $p=1 / n$. Now suppose that you purchase a burglar alarm that can always detect a thief should he attempt to break into your house and you publicize that your house is protected in this way. The risk of a loss to your house is now 0 , independent of what other houses have done. In other words, there is no possible contamination from other houses in the area as in the interdependent security problem. In fact, there is now an increase in the probability that one of the other houses in the neighborhood will be robbed. Let $p^{\prime}$ represent this revised

\footnotetext{
${ }^{11}$ We appreciate a helpful discussion with Daniel Kahneman on this point
} 
probability of a theft with $p^{\prime}>p$. In the case of random theft, your house is off-limits and the other $n-1$ houses have a $p^{\prime}=1 / n-1$ chance of being burglarized. In other words, installing a burglar alarm imposes a negative externality by shifting crime to those who are unprotected.

If all homes are identical then there will be two Nash equilibria just as in the interdependent security problem, but the solution is now much more straightforward because there is no contamination. If the cost of the burglar alarm is $c$ and individuals are risk neutral then no one will invest in a burglar alarm if $c>p L$. If $c<p L$ then everyone will want to protect themselves. Recall, however, that $p$ is here endogenous and depends on who has invested in an alarm.

Suppose that instead of publicly revealing that one has a burglar alarm, one informs the local police that this action has been taken, so that criminals cannot determine who is protected. In this case installing an alarm system does not reduce the probability that an individual house will be broken into. It may however provide a positive externality by reducing the chances of a crime occurring in the community if the burglars know that a certain percentage of homes are protected. This type of unobservable precaution is similar to the Lojack car retrieval system. Ayres and Levitt (1998) show that the marginal social benefit of an additional unit of Lojack is as much as 15 times greater than the marginal social cost in high crime areas. However, those who install Lojack in their cars obtain less then 10 percent of the total social benefits associated with this protective measure.

\section{Vaccinations}

The decision on whether to get vaccinated is similar in some ways but also differs from the interdependent security problem. Clearly there are externalities here: if I am vaccinated against a disease, you will not catch it from me. So one person investing in protection conveys 
positive externalities on others, as in the interdependent security problems discussed in this paper. ${ }^{12}$ This much is common to both issues.

Consider however the Nash equilibria that may arise when people decide whether or not to be vaccinated. Suppose that tomorrow an effective vaccine against influenza is approved for general use. When choosing whether to be vaccinated or not, each person has to anticipate the choices of others. If everyone else were to be vaccinated, then there would be no point in my being vaccinated, as I would be in no danger of catching the flu. At the other extreme, if I believed that most people would not be vaccinated, this would increase my incentive to be vaccinated.

From this we can see that if the vaccination cost is sufficiently low and the risk is sufficiently high then a situation where no one is vaccinated cannot be a Nash equilibrium. ${ }^{13}$ On the other hand, everyone being vaccinated is also not a Nash equilibrium, for if I believe that everyone else will get vaccinated then I will not want to be vaccinated. In contrast to the interdependent security problem discussed in this paper the Nash equilibrium will be a mixture of Ns and Ss even when all individuals are identical. Some individuals will decide to get vaccinated while others prefer to be unprotected. Those who decide to get vaccinated will have no incentive to change their minds because there will be enough people who are unprotected so that the chances of being contaminated and contracting the disease will be greater than the cost and potential side-effects of the vaccine. Similarly those who have not protected themselves will

\footnotetext{
${ }^{12}$ Philipson (2001) has a nice summary of recent research on economic epidemiology and the role that vaccines play in reducing the spread of diseases.

${ }^{13}$ See Hershey et al (1994) for a more detailed discussion of the role that free riding, and bandwagoning play in vaccination decisions.
} 
find that the expected costs and side-effects of the vaccine will exceed the expected benefits from being protected. ${ }^{14}$

\section{Future Research}

The decision as to whether one wants to undertake protection against events where there is interdependence between your actions and those of others raises a number of interesting theoretical and empirical questions. We discuss some of these issues in this section.

\section{Differential Costs and Risks}

The nature of stable Nash equilibria for the problems considered above and the types of policy recommendations may change as one introduces differential costs across the agents who are considering whether or not to invest in security.

Consider each airline deciding whether to invest in a baggage security system. As pointed out in Section 2, if there are differential costs and/or risks between companies, we would expect to find a stable Nash equilibrium that consisted of a combination of S's and N's. Some agents would have low enough costs that they would want to invest in the protective measure while others would find it too expensive.

One needs to reexamine the types of prescriptive recommendations for dealing with the issue of differential risks and/or costs. For example, suppose that some airlines had a greater chance of contaminating others because they had more bags transferred to other airlines. Should one tax them more if they do not invest in a baggage security system? If differential taxation is not feasible for political reasons should one resort to other regulations to deal with the interdependent security problem? One option would be to require only bags that are transferred

\footnotetext{
${ }^{14}$ We thank Richard Zeckhauser for pointing out this feature of the Nash equilibrium to us.
} 
to other airlines to go thru a security system. This would avoid the problem of negative externalities. $^{15}$

\section{Multi-Period and Dynamic Models}

The decision on whether or not to invest in security normally involves multi-period considerations since there is an upfront investment cost that needs to be compared with the benefits over the life of the protective measure. An airline that invests in a baggage security system knows that this measure promises to offer benefits for a number of years. Hence one needs to discount these positive returns by an appropriate interest rate and specify the relevant time interval in determining whether or not to invest in these actions. There may be some uncertainty with respect to both of these parameters.

From the point of view of dynamics, ones own decision on whether to incur the cost of protection depends on how many others have taken similar actions. How do you get the process of investing in security started? Should one subsidize or provide extra benefits to those who are willing to be innovators in this regard to encourage others to take similar actions? In order to answer these and other questions one needs to develop sequential models of decision-making. These models will need to consider the special characteristics of the hazard and the nature of the contamination effects. A dynamic model for airline or computer security will have a different set of interactions than one for theft protection or immunization against specific diseases. The policy recommendations will also reflect these differences.

\section{Behavioral Considerations}

The models we have developed and discussed above all assumed that individuals made their decisions by comparing their expected benefits with and without protection to the costs of investing in security. We will label this a rational model of behavior.

\footnotetext{
${ }^{15}$ We thank Ido Erev for suggesting this option to us.
} 
There is a growing literature in behavioral economics that suggest that individuals make choices in ways that differ from the rational model of choice. (Kahneman and Tversky 2000). With respect to protective measures there is evidence from controlled field studies and laboratory experiments that many individuals are not willing to invest in security for a number of reasons that include myopia, high discount rates and budget constraints. (Kunreuther, Onculer and Slovic 2000). In the models considered above there were also no internal positive effects associated with protective measures. Many individuals invest in security to relieve anxiety and worry about what they perceive might happen to them or to others so as to gain peace of mind (Baron, Hershey and Kunreuther 2000). ${ }^{16}$

A more realistic model of interdependent security that incorporated these behavioral factors as well as people's misperceptions of the risk may suggest a different set of policy recommendations than would be implied by a rational model of choice. For example, if agents were reluctant to invest in protection because they were myopic, then some type of loan may enable them to discern the long-term benefits of the protective measure. A long-term loan would also help relieve budget constraints that may deter some individuals or firms from incurring the upfront costs of the risk-reducing measure.

\section{Future Empirical Studies}

The issues discussed above suggest a number of empirical studies on interdependent security. Given the concern with terrorism both in the United States and the rest of the world it would be interesting to learn more about the factors which are leading some organizations to invest in security and why others are deterred from doing so.

\footnotetext{
${ }^{16}$ Of course, if these individuals become aware that substantial losses may be imposed on them or their firm from others who are unprotected, then this new knowledge may increase their anxiety by showing that investing in these protective measures has more limited benefits than they had initially assumed it would.
} 
What actions can the public sector take in encouraging property owners and organizations to invest in certain protective measures? What are the appropriate roles of taxation, regulations and standards (e.g. well-enforced building codes)? How can market mechanisms such as insurance, bank loans and potential liability aid in this process? What institutional mechanisms would aid the decision process of agents regarding protective measures when others will be affected? Can industry associations, like IATA for the airlines, play an important role in facilitating actions by individual companies?

\section{Concluding Comments}

The events of September $11^{\text {th }}$ have highlighted the importance of addressing the questions associated with interdependent security. This paper should be a viewed as a first step in providing a framework for undertaking future theoretical and empirical studies in this area. By

developing a richer set of models and testing them through controlled experiments and field studies we are hopeful that a viable set of policies will emerge for dealing with the challenges we face today in dealing with hazards where there are risks of contamination. 


\section{REFERENCES}

Arthur, Brian (1994) Increasing Returns and Path Dependence in the Economy. Ann Arbor: University of Michigan Press.

Ayres, Ian and Steven Levitt (1998) "Measuring the Positive Externalities from Unobservable Victim Precaution: An Empirical Analysis of Lojack" Quarterly Journal of Economics 113: 4377.

Baron, Jonathan., Hershey, John. and Kunreuther, Howard. (2000). Determinants of priority for risk reduction: the role of worry. Risk Analysis, 20, 413-427.

Cohen, Linda and Noll, Roger (1981) "The Economics of Building Codes to Resist Seismic Shocks" Public Policy Winter 1-29.

Heal, Geoffrey (1994). "Formation of International Environmental Agreements," in C. Carraro (ed.) The International Dimension of Environmental Policy, Boston: Kluwer.

Heal, Geoffery (1999a) "Price and Market Share Dynamics in Network Industries". Chapter 10 of G. Chichilnisky (ed) Markets, Information and Uncertainty: Essays in Honor of Kenneth J. Arrow. New York: Cambridge University Press.

Heal, Geoffrey (1999b) "New Strategies for the Provision of Global Public Goods: Learning from international environmental challenges." in I Kaul and M. Stern (ed) Global Public Goods New York: Cambridge University Press.

Hershey John, Asch D, Thumasathit T, Meszaros J, and Waters V, (1994) "The Roles of Altruism, Free Riding, and Bandwagoning in Vaccination Decisions," Organizational Behavior and Human Decision Processes 59:177-187.

Kahneman, Daniel and Tversky, Amos (2000) Choices, Values and Frames New York: Cambridge University Press.

Kleindorfer, Paul and Kunreuther, Howard. (1999). "The Complementary Roles Of Mitigation And Insurance In Managing Catastrophic Risks." Risk Analysis, 19:727-38.

Kunreuther, Howard, Onculer, Ayse and Slovic Paul (1998) "Time Insensitivity for Protective Measures” Journal of Risk and Uncertainty, 16: 279-299.

NY Times (2002) “Airlines Scramble to Meet New Bag Check Deadline” January 14. 
Orszag, Peter and Stiglitz, Joseph (2002) “Optimal Fire Departments: Evaluating Public Policy in the Face of Externalities" January (mimeo).

Ostrom, Elinor. (1990) Governing the Commons: The Evolution of Institutions for Collective Action. Cambridge, UK: Cambridge University Press.

Philipson, Tomas (2001) "Economic Epidemiology and Infectious Diseases" in Joseph Newhouse and Anthony Culyer eds The Handbook of Health Economics North Holland Press.

Schelling, Thomas (1978) Micromotives and Macrobehavior New York: Norton.

Sunstein, Cass (1996) "Social Norms and Social Roles," Columbia Law Review 96:903-68. 